BULLETIN Bulletin hispanique

HISPANIQUE Université Michel de Montaigne Bordeaux

$112-2 \mid 2010$

Varia

\title{
Aurora Egido, El Barroco de los modernos. Despuntes y pespuntes
}

Cátedra Miguel Delibes, Valladolid, 2009

Ignacio García Aguilar

\section{CpenEdition}

\section{Journals}

Edición electrónica

URL: http://journals.openedition.org/bulletinhispanique/1294

DOI: 10.4000/bulletinhispanique.1294

ISSN: 1775-3821

\section{Editor}

Presses universitaires de Bordeaux

\section{Edición impresa}

Fecha de publicación: 31 diciembre 2010

Paginación: 852-858

ISBN: $978-2-86781-709-0$

ISSN: 0007-4640

\section{Referencia electrónica}

Ignacio García Aguilar, « Aurora Egido, El Barroco de los modernos. Despuntes y pespuntes », Bulletin hispanique [En línea], 112-2 | 2010, Publicado el 19 enero 2013, consultado el 23 septiembre 2020. URL : http://journals.openedition.org/bulletinhispanique/1294 ; DOI : https://doi.org/10.4000/ bulletinhispanique.1294 
est une contribution de première importance aux études gongorines " ( $p$. 32). Aussi nous a-t-il semblé intéressant d'effectuer un rapide pointage : 86 textes figurent dans les deux anthologies, 114 se trouvent seulement dans celle de Carreira et 30 seulement dans celle de Jammes. C'est dire que ces deux ouvrages, d'une rigueur philologique parfaite, sont complémentaires. Outre un très large éventail de poèmes, ils offrent dans les centaines de notes et de notices qui accompagnent les textes une mine de renseignements de tous ordres non seulement sur la poésie de Luis de Góngora mais aussi sur la langue, la société et les mœurs du Siècle d'Or.

Jacques IsSOREL

Aurora Egido, El Barroco de los modernos. Despuntes y pespuntes. - Valladolid, Cátedra Miguel Delibes, 2009, 292 p.

El análisis de los problemas sobre recepción, canon y conformación de una tradición literaria se enriquece ahora, y mucho, con el Barroco de los modernos. Despuntes y pespuntes de Aurora Egido. El libro es el resultado de ordenar y disponer editorialmente el trabajo preparado por la autora para participar en un curso de doctorado en el Graduate Center de la Universidad de Nueva York (CUNY), que versó sobre el modo en que los principales escritores e intelectuales hispanos de inicios del XX leyeron lo barroco antes de que tuviera lugar el homenaje a Góngora de 1927. La indagación en estas múltiples lecturas permite a Egido a explicar cómo hicieron suyo lo barroco, de acuerdo a distintos y particulares condicionantes, y cómo lo proyectaron, en lo sucesivo, hacia los lectores futuros. Estructurado en diez capítulos, el libro traza un sólido itinerario intelectual y metodológico en el que se va desgranando la consideración que los autores del XVII tenían de las innovaciones que estaban modificando el sistema de la literatura en su tiempo, así como la manera en que los modernos autores de principios del $\mathrm{XX}$ entendieron lo barroco y trataron de explicarlo, con soluciones de muy distinta índole.

Se abre el libro con unas consideraciones previas sobre lo barroco y sobre la manera en que dicho concepto se puede revelar operativo y fructífero para un estudio cabal de las relaciones entre el XVII y el XX. Conforme a ello, plantea Egido la necesidad metodológica de rebasar el estudio de las formas e indagar en el contexto en el que estas se crean, aplicando un itinerario crítico de doble sentido que permita llevar el análisis del XVII hasta el XX, momento que en «al inventarse el término historiográfico y crítico, la propia 
mentalidad moderna de la época lo define y limita desde sus propios gustos» (p. 17). Pero la indagación en las raíces o en el origen de lo barroco -en tanto que concepto categorizador y definitorio de formas de organización cultural en una diacronía extensa- no es el objeto de este estudio. Lo que interesa a la autora es reconstruir la concepción que ciertos escritores de España e Hispanoamericana tuvieron de lo barroco antes del homenaje de 1927.

En el contexto de la crisis del fin de siglo y al calor de las críticas que suscitó el Modernismo entre un importante sector de la literatura española no deja de ser significativo que autores como Emilio Ferrari denuesten las nuevos modelos apelando a superficiales cuestiones de cobertura formal: «Y tendrás esa jerga soberana / que es Góngora vestido a la francesa / y pringado en compota americana». Resultan evidentes los paralelismos con muchas de las críticas que soportó la poesía innovadora de Boscán y Garcilaso, en el XVI, y de Góngora y sus seguidores en la centuria siguiente. Es claro, por tanto, que la añeja y farisaica división entre culteranos y conceptistas se había trasladado a lo de los casticistas y modernistas.

Pero hubo quien profundizó mucho más y con mayor acierto que la mayoría de sus contemporáneos en la esclerosada dicotomía conceptismoculteranismo. En el segundo capítulo del volumen expone Egido cómo Machado apreciaba la capacidad de condensación lingüística de Góngora, aunque su distinción entre la metáfora como expresión de lo intuitivo y la que es simple cobertura formal le llevaba ser contario al uso de este recurso cuando no suplía una carencia nominal o conceptual. Así pues, Machado se adelantó en su análisis sobre la metáfora a Ortega, Lorca, Dámaso Alonso y otros miembros del 27. Sin embargo, su concepción de lo ideal poético alejaba a la poesía barroca del lenguaje lírico, y le permitió vislumbrar, como al Gracián de la Agudeza, que la metáfora culterana no desmerecía en lo conceptual del concepto conceptista, valga la redundancia. Estas valoraciones revelan que además de gran lector de la poesía barroca Machado debió de conocer bien a los comentaristas gongorinos y que entendió de manera distinta a la de muchos de sus pares que no existían diferencias radicales entre culteranos y conceptistas, ya que en lo esencial tanto unos como otros «transitaban por los mismos derroteros, carentes de ideas y sumidos en juegos metafóricos y conceptuales, sin intuición, sin gracia y sin vida» (p. 59).

Aunque en una dirección opuesta, Azorín compartió con Machado el desacuerdo con respecto a la simplificación reduccionista y distorsionadora entre culteranos y conceptistas que habían fijado las sucesivas historias de la literatura. Concebía el culteranismo como «la más alta expresión del movimiento en el lenguaje» (p. 66), y esa idea de una forma en acción se adelantaba un cuarto de siglo a la que plantearían posteriormente algunos 
de los poetas del 27. El capítulo tercero revela que Azorín supo ver el valor dinámico de la literatura y ello le permitió conectar a Gracián con Schopenhauer y Nietzsche, marcando así importantísimas pautas para estudios posteriores, al tiempo que situaba su propia escritura en relación a modelos previos, pues su prosa lacónica debe mucho a la actualización del jesuita, lo que abrió, además, «un ancho camino en las letras españolas e hispanoamericanas con el cultivo de un nuevo aticismo» (p. 67). En Los dos Luises y otros ensayos (1921) reivindicó, antes de que lo hicieran los jóvenes del 27, la modernidad de Góngora al subrayar su capacidad de evocar la belleza natural y construir una poesía sensorial de luces y colores, justo lo contrario al manto de oscuridad con el que lo había recubierto la crítica neoclásica. De ese modo, el reconocido artífice de letrillas y romances iba dejando paso al grandísimo escritor de los sonetos y los poemas mayores. Pero serían Cervantes y Lope los autores predilectos de Azorín. Al uno reconocía su cosmopolitismo y la justeza de la prosa; al otro, ser un depurador máximo de la realidad y sintetizador de Garcilaso, Herrera, Castillejo e incluso Góngora. El marcado carácter divulgativo de estas reflexiones contribuyó grandemente a la difusión de la literatura áurea, filtrada, eso sí, por la visión azoriniana, entre un amplio y variado espectro de lectores españoles e hispanoamericanos.

Si Machado y Azorín marcan una fractura con la interpretación aceptada en el ámbito peninsular, Pedro Henríquez Ureña y Alfonso Reyes ofrecen, a caballo entre las dos orillas, alternativas a la lectura interpretativa de lo barroco. La versificación irregular en la poesía castellana (1920), de Henríquez Ureña, publicado un año antes que Los dos Luises, es de capital influencia no sólo en la creación poética de la Generación del 27, sino también en el estudio crítico de la métrica en el ámbito de análisis filológico. Ya en 1905, y por lo novedoso de su métrica, había definido Ureña a Rubén Darío «como un Góngora desenfrenado y corruptor» (p. 86). Su mirada crítica también se fijó sobre otra dicotomía inamovible que debe sumarse a las ya mencionadas: se trata de las traídas y llevadas dos épocas de Góngora, que él desecha, pues pese a las construcciones críticas que imperaban entonces, entiende con gran acierto que existe en la escritura del cordobés evolución y continuidad, y no escisión o ruptura.

También Reyes disiente de los inmovilistas presupuestos críticos de su tiempo en lo concerniente a Góngora, y embiste con vigor contra quienes afirman que Lope y Góngora representaban modelos contrapuestos de extensión e intensión, respectivamente. Desbordó en su análisis la tradicional oposición entre culteranos y conceptistas por la vía de los valores conceptuales 
propios de los contrarios a Góngora, lo que suponía un acercamiento distinto, en el que los comentarios del XVII eran el hilo para salir del laberinto. En sus Cuestiones estéticas elabora el concepto de intensificación, tan fructífero en la crítica gongorina posterior desde Dámaso Alonso a Lázaro Carreter. Erige al cordobés en el mayor poeta de la tradición española y subraya la musicalidad y colorismo de la poesía de Góngora, así como los vínculos de ésta con Mallarmé, elementos todos ellos en los que repararía de modo sustantivo la crítica posterior. Entre 1914 y 1924 la obra de Reyes está llena de referencias a la literatura áurea española, en paralelo a lo que estaban haciendo Azorín y Ortega, a los que cita con frecuencia; y en el mismo 1927 publica sus Cuestiones gongorinas. Reyes, además de agudo lector, es un riguroso crítico que se vale de las herramientas de la ecdótica y la hermenéutica para sus lecturas, trabajando preferentemente con fuentes primarias. Por todo ello, y por sus interpretaciones alternativas, está justamente en la vanguardia crítica de sus contemporáneos.

En el quinto capítulo se analiza cómo Ortega y Gasset contribuyó a la institucionalización del término Barroco y a su incorporación a la crítica, tanto artística como literaria, lo que facilitó grandemente su posterior utilización en el terreno historiográfico. Aurora Egido destaca la importantísima "penetración del concepto de Barroco en su obra», lo que permite «afirmar que está mucho más presente en él que en cualquiera de los autores del 27, incluido Dámaso Alonso en sus tempranos estudios gongorinos» (pp. 120-121). Pero lo barroco en Ortega debe entenderse a la luz de los presupuestos de Wölfflin, el discípulo de Burckhardt, cuya obra Los conceptos fundamentales de la historia del arte tradujo el propio Ortega, asumiendo muchos de sus postulados. Así, por ejemplo, en su análisis de la poesía gongorina Ortega incluyó las nociones wolfflinianas de movimiento y línea curva, de tanta recurrencia en la crítica posterior. Recurre, asimismo, a conceptualizaciones de vital importancia y fecundidad ulterior, las cuales «apuntan en una dirección esencial hacia la que se dirigiría la mayor parte del gongorismo del 27 y de sus seguidores [...] la sustitución del concepto o idea por la imagen» (p. 141). Por otro lado, elimina la oposición luz/oscuridad, pues no cree que las Soledades sean más complejas que los romances, aunque las prefiere a estos. En su "Góngora, 1627-1927» plantea una visión biológica de la obra del cordobés, y habla de su escritura como una suerte de ser viviente en ascenso hacia «la nube culta, pero asentando sus raíces en el humus del realismo poético» (p. 139). En el proceso de lectura y ajuste que se está produciendo por estos ańos no carece en absoluto de importancia que fuese precisamente Ortega quien impulsara la celebración del aniversario 
por la muerte de Mallarmé (autor de tanta incidencia en la revalorización del poeta cordobés), adelantándose en varios años al homenaje de la Generación del 27.

Algún tiempo antes, D’Ors había anticipado su valoración del barroco en las líneas de un artículo dedicado a Churriguera y, sobre todo, en su Tres horas en el Museo del Prado (1922), al plantear la antítesis entre un concepto de lo clásico entendido como razón, equilibrio y mesura, y la irracionalidad, instinto y sensualidad en se cifraban las características de lo barroco. De ese modo, lo barroco no era ya concebido como un fenómeno vinculado a un momento histórico concreto, sino que se trataba, coincidiendo con Wölfflin, de una constante histórica susceptible de manifestarse en cualquier momento y sujeta a evolución constante, pero sin condicionamientos geográficos o cronológicos.

Desde los primeros tiempos de las vanguardias, el lenguaje poético del XVII y la propia noción de lo barroco estuvieron en el punto de mira de los creadores e intelectuales del momento. Así, Guillermo de Torre, en Literaturas europeas de Vanguardia (1925), asume lo barroco en diferentes niveles y como un fenómeno de gran modernidad que no es ajeno a la estética de su propio tiempo. Considera que Góngora es el primer clásico de la tradición española y precursor de las indagaciones metafóricas de los ultraístas. Gómez de la Serna, por su parte, privilegia a Lope y Quevedo sobre cualquier otro, al tiempo que asume lo barroco en una doble perspectiva, en su dimensión lingüística de retorsión y dificultad, por un lado, y en tanto que hallazgo y novedad de nuevas vías, por otro. Bergamín estableció un diálogo desde la vanguardia con la tradición previa, caracterizado por el sincretismo y fuertemente influenciado por Wölfflin. Conforme a esto, Góngora, San Juan, Cervantes, Quevedo o Calderón son rescatados (releídos y rescritos) y se hacen presentes en las páginas de Bergamín, con la certeza de que «todos eran barrocos y que lo que el tiempo había desunido, el presente lo hacía posible» (p. 173)

El homenaje del 27 a Góngora era una puesta en valor de la poética del autor de las Soledades, sin duda; pero supuso, sobre todo, un basamento y una herramienta de autoafirmación, individual y corporativa, de toda una generación de poetas con ciertas afinidades. Gerardo Diego, como otros de su generación, contribuyó a construir su propio espacio y el de sus compañeros en el canon literario por muy distintas vías, y la reivindicación gongorina fue una de ellas. Las coincidencias que establece con Mallarmé le sirven para dotar de modernidad y actualidad a la poesía del cordobés; pero junto a ello, no deja de ser significativo que salve a algunos poetas del 
XVIII empapados en algo de Góngora - como León y Mansilla o el Conde de Torrepalma - y condene sin excepción a todo el parnaso decimonónico. Se hace evidente, entonces, su interés particular en salvar a algunos poetas dieciochescos y defenestrar a toda la poesía del XIX, de la que estaba más cerca cronológicamente y de la que deseaba alejarse literaria e institucionalmente.

Probablemente, nadie del 27 como Dámaso Alonso expuso más por extenso sus juicios sobre el poeta cordobés. La lengua poética de Góngora, escrito en 1927 pero difundido a partir de 1933, supone una detallada indagación en el estilo del autor, aunando el análisis de léxico, sintaxis, metáfora, hipérbole y colorismo. La apuesta por la vía estilística eliminaba los dos Góngoras heredados de la historiografía neoclásica y canonizados por Menéndez Pelayo. A la negación de las dos épocas se sumaba, sin embargo, una fractura en el año 1610, que suponía un cambio propiciado por la mayor intensión en el estilo del cordobés. Por otro lado, con su «Escila y Caribdis en la literatura española», también de 1927, estableció Dámaso Alonso una contraposición entre Lope y Góngora que, pese a sus diferencias específicas, los aunaba y validaba como poetas en un contexto historiográfico común. Aunque Dámaso Alonso utiliza raramente una nomenclatura ligada al campo semántico del Barroco y lo barroco, conocía sin duda la obra de Wölfflin; sin embargo, su aplicación como fractura con todo lo anterior y novedad con respecto a la literatura previa le generaba contrariedades, ya que, al igual que los de su generación, concebía la existencia de una línea de continuidad que atravesaba toda la poesía del XVII, también la del XVIII e incluso penetraba en el Romanticismo.

Tampoco Guillén apreciaba fractura entre la poesía del XVI y el XVII, a la que evitaba referirse con el marbete de Barroco. Su estancia en la Sorbona como lector le hizo empaparse de la estética francesa, lo que influiría inevitablemente en sus reflexiones ulteriores sobre la poesía del cordobés. En su tesis doctoral afirma la necesidad de recuperar a los comentaristas (Díaz de Rivas, Salcedo, Pellicer, Cuesta), aunque él no les dedica demasiada atención y se preocupa más de acercar a Góngora a la poesía de su momento. $\mathrm{Y}$ ello explica que, en un momento en el que el neogongorismo se acerca decididamente al estudio de la metáfora y los poemas mayores, Guillén se detenga en el repertorio popular gongorino, pero no para ahondar en la metáfora, sino en las imágenes. Trataba así de transmutar algunos de esos poemas en "poesía pura» y lograr la conjunción de su propia estética con la poesía del autor de las Soledades. Con su lectura de Góngora, interesadamente acotada, no pretendía otra cosa distinta a la de muchos otros del grupo del 27: «equipararse a una variedad genérica, estilística y temática que los glorificara y comprendiera en su propia evolución poética» (p. 261). 
Este volumen, en fin, reconstruye con un despliegue de conocimientos y de rigor muy poco común las lecturas, relecturas, interpretaciones y cadena de referentes que hilvanaron las trayectorias intelectuales de los poetas y críticos del primer tercio del siglo XX; y todo ello partiendo de la recuperación, actualización y construcción de la idea de Barroco y de la poesía de Góngora, principalmente; aunque también hay sitio en este denso estudio para Gracián, Lope, Quevedo, Cervantes y otros muchos. Recorrido el itinerario que propone la autora, desde el Modernismo a la Generación del 27, se entiende cabalmente el título de su trabajo, pues con sus despuntes y pespuntes Aurora Egido sutura la grieta que separaba lo barroco del XVII de ese Barroco de los modernos, que aún hoy actualizan y modifican los postmodernos para generar un concepto de Neobarroquismo válido en el siglo XXI.

Ignacio García Aguilar

Manolo Valiente, Du Barcarès à Bram et d'Argelès au Barcarès... Un artiste en camp de concentration (1939-1942). Del Barcarès a Bram i d'Argelers al Barcarès... Un artista als camps de concentració (19391942). Éric Forcada (dir.). - Perpignan, Mare Nostrum, 2010, 220 p. : ill. (Col-lecció Carl Einstein. Ars als camps de concentració, 1). ISBN 978-2-908476-87-3.

Ce superbe ouvrage a été publié à l'occasion de l'exposition (janviermars 2010) consacrée à Manolo Valiente (Manuel Pérez Valiente) par le Museu Memorial de l'Exili de La Jonquera (Gérone). Soixante et onze ans plus tôt, Valiente franchissait à pied la frontière par la montagne, fuyant, comme quelque 500.000 de ses compatriotes, devant l'avancée des troupes franquistes. Blessé sur le front de Somosierra en 1937, il se vit, une fois en terre française, ballotté à travers divers hôpitaux avant de se retrouver enfermé dans trois camps de concentration : Argelès, Bram et le Barcarès. À sa libération, en novembre 1942, il décida de demeurer dans les PyrénéesOrientales où il vécut jusqu'à sa mort le 30 juin (et non le 3 juin, p. 54) 1991 à Perpignan (et non à Banyuls-sur-Mer, ibid.). Peintre et sculpteur, Valiente est aussi l'auteur d'un recueil de poèmes publié en 1949, Arena y viento, réédité en 1973 et 1986. Récemment ont vu le jour aussi deux de ses œuvres inédites: Arena y viento. Segundo libro et Un rojillo en el sur de Francia (Mare Nostrum, Perpignan, 2009) ${ }^{16}$.

16. Voir compte rendu par Aymat Catafau Pajerols dans Bulletin hispanique, t. 111, n 2, décembre 2009, p. 679-680. 